\title{
Effects of Nicotiana tobaccum extract additive on the quality of electroplating of zinc on mild steel
}

\author{
C.A. Loto ${ }^{1,2}$, R.T. Loto $^{2}$ \\ ${ }^{1}$ Covenant University, Department of Mechanical Engineering, Ota, Nigeria \\ ${ }^{2}$ Tshwane University of Technology, Department of Chemical and Metallurgical Engineering, Pretoria, South Africa \\ "Corresponding author: akinloto@gmail.com
}

\begin{abstract}
Experimental investigations have been performed to determine the effects of nicotiana tobaccum (tobacco) extract additive on the electrodeposition of zinc on mild steel in acid chloride solution. The experiments were performed under different plating time, different additive concentrations and fixed $\mathrm{pH}$ conditions. Zinc electrodeposition on mild steel was performed using a DC - supply at defined operating parameters. The surface of the plated steel was examined using scanning electron microscopy (SEM); and Energy Dispersive Spectroscopy (EDS) for the surface elemental composition analysis. Different surface characteristics were obtained depending upon the concentration of the additive and the plating time. The corrosion resistance of the plated surface was also determined by a gravimetric method. The quality of the electro-deposition of zinc was good as indicated by the microstructural morphology of the plated surface except for the few porosities observed. The electrodeposition process was sensitive to the changes in the additive concentration and plating time. Any variation in the plating parameter produced an enirely new and different surface morphology.
\end{abstract}

Keywords: Electrodeposition, tobacco, steel surface, acid chloride solution, corrosion.

\section{INTRODUCTION}

Though the commercially-available proprietary additives $^{1-4}$ have now been used for some years, the need to develop other environment - friendly non-commercial proprietary additives for the acid chloride bath has been generating increased research interest including the present investigation. The need to prevent corrosion and toxicity and to enhance the aesthetic value of steel components in different manufacturing productions, industries and services facilities and in our daily lives adds to the growing interest in this field of electrodeposition research. This work is also a further contribution to the recent investigations ${ }^{5-9}$ which characterized the surface effects of additives on the electrodeposition of zinc on mild steel in acid-chloride solution under different conditions. Many other authors ${ }^{10-13}$ have also reported in different areas of zinc and zinc alloys electrodeposition and on synergistic effect of electrodeposited alloys/effect of addition agents and also on their corrosion resistance characteristics using different bath solutions.

Chloride zinc solution does not only eliminate cyanide in plating, it also gives improved bath efficiency and exceptional brightness. And zinc baths are used where it is desirable to have a high plating rate and low cost. Chloride zinc plating offers considerable advantages over cyanide-based systems, although it is not without its share of routine operating problems ${ }^{3}$. Use of the acid sulphate process is increasing due to its relatively low cost, safety features and pollution control characteristics, but throwing power and insufficient brightness from an acid sulphate bath are disadvantages ${ }^{9}$.

The use of plant extracts as inhibitors for the corrosion of metals/alloys has been well documented among researchers in recent time ${ }^{\mathbf{1 4 - 2 2}}$. However, the application of these plant extracts to electrodeposition of zinc on metallic alloy such as mild steel, is very new. Some previous work on extracts of tobacco (genus - Nicotiana: family - Solanaceae), as an environmental benign corrosion inhibitor ${ }^{15-18,23}$ had shown it to be effective in preventing the corrosion of steel and aluminium in saline environments; and in fact, exhibiting a greater corrosion inhibition effect than chromates ${ }^{8-19}$. Tobacco plants produce $\sim$ 4,000 chemical compounds - including terpenes, alcohols, polyphenols, carboxylic acids, nitrogen - containing compounds (nicotine), and alkaloids ${ }^{23}$. These complex chemical compositions may exhibit electrochemical activity such as electrodeposition. A good result in this work will be of significant technological and economic benefit.

\section{MATERIALS AND METHODS}

The tobacco extract was obtained from the leaves which were sun-dried for 10 days before being ground to the powder form in order to increase the surface area for extraction. Two portions of ground tobacco leaves weighing $137 \mathrm{~g}$ each were soaked in $420 \mathrm{ml}$ of ethanol for 5 days. The ethanol was then boiled off on a heating mantle using a simple distillation set to collect the ethanol that was used. $30 \mathrm{~g}$ of the concentrated tobacco extract was obtained after the distillation process. The gelatinous extract was then dissolved in $300 \mathrm{ml}$ of distilled water to obtain a concentration of $0.10 \mathrm{~g} / \mathrm{ml}$ $(100 \mathrm{~g} / \mathrm{l})$. The solution was stirred vigorously to ensure that the tobacco was properly dissolved.

\section{Experimental set-up}

Flat mild steel, SIS 14147, $0.1 \mathrm{~cm}$ thick, with a nominal composition of $0.038 \% \mathrm{C}, 0.195 \mathrm{Mn}$ and the remainder $\mathrm{Fe}$, was cut into several test specimens of $10.0 \mathrm{~cm}$ long and $1.0 \mathrm{~cm}$ wide. A portion of $1.0 \mathrm{~cm}$ in length was marked off at one end for the electrodeposition of zinc. The test specimens were degreased ultrasonically for 5 minutes with an alkaline degreasing chemical - Henkel VR 6362-1, and then removed from the solution, rinsed in distilled water, immersed in methanol, and air-dried. The specimens were, in turns, etched for 50 seconds 
in $3 \mathrm{M} \mathrm{HCl}$, rinsed in distilled water, immersed in methanol, air dried and stored in a desiccator for further experimental process.

The acid chloride solution for the electrodeposition consisted of $\mathrm{ZnCl}(71 \mathrm{~g} / \mathrm{l}), \mathrm{KCl}(207 \mathrm{~g} / \mathrm{l})$ and $\mathrm{H}_{3} \mathrm{BO}_{4}$ $(35 \mathrm{~g} / \mathrm{l})$. Solution extracts of Nicotiana tobaccum (Tobacco) of varying concentrations $-4,5,6 \mathrm{ml} / 50 \mathrm{ml}$ of acid chloride solution were used in turns as the addition agents (Table 1).

Table 1. The bath addition agent and concentration used

\begin{tabular}{|c|c|c|}
\hline Additive & $\begin{array}{c}\text { Quantity of additive } / 50 \mathrm{ml} \text { of } \\
\text { acid chloride }\end{array}$ & \% Concentration \\
\hline Tobacco & $4.0 \mathrm{ml}(80 \mathrm{ml} / \mathrm{L})$ & 8 \\
& $5.0 \mathrm{ml}(100 \mathrm{ml} / \mathrm{L})$ & 10 \\
& $6.0 \mathrm{ml}(120 \mathrm{ml} / \mathrm{L})$ & 12 \\
\hline
\end{tabular}

Electrodeposition of zinc on steel was performed by partially immersing the steel specimen and the zinc electrodes in the plating solution (20 $\mathrm{mm}$ deep) through the rectangular hole made on - a prepared perspex cover for the $250 \mathrm{ml}$ beaker used as the plating bath. The steel specimen was connected to the negative side of a DC supplier while the zinc electrodes were also connected with a wire to the positive side, Fig. 1. The plating solutions were put in turns into the beaker and their respective $\mathrm{pH}$ was obtained by adjusting the original solution with potassium hydroxide. The plating times used for each bath were 15 and 18 minutes. The weight of the steel specimen was taken before and after the electroplating process in order to determine the weight of zinc deposit by finding the difference between both weight readings, (Table 2).

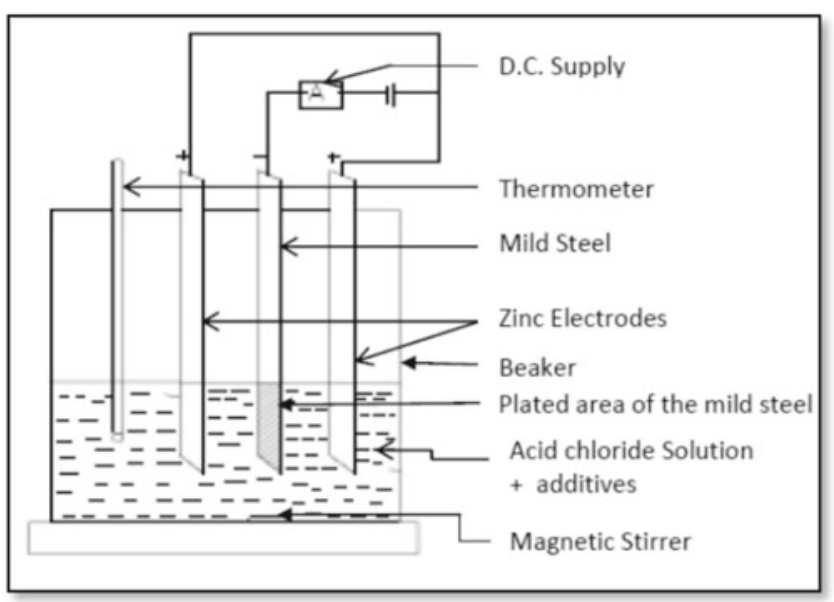

Figure 1. Schematic diagram of the experimental set-up

Table 2. Mass of zinc deposited on steel substrate during plating

\begin{tabular}{|l|c|}
\hline Sample & Mass Deposited $(\mathrm{g})$ \\
\hline A1 & 0.243 \\
B1 & 0.0283 \\
\hline E1 & 0.0293 \\
\hline F2 & 0.0246 \\
\hline M2 & 0.0241 \\
\hline N1 & 0.0283 \\
\hline
\end{tabular}

The plating solution was stirred gently while the plating was being carried out to ensure even plating. The other operating conditions were: $\mathrm{pH}$ of the solution, 5; temperature, $27-30^{\circ} \mathrm{C}$; current $0.08 \mathrm{~A}$; Voltage, $13 \mathrm{~V} \mathrm{DC}$; plating time, 15 and $18 \mathrm{~min}$. After each plating experiment, the specimen was taken out, rinsed in distilled water, immersed in methanol, and quickly air-dried. The specimens were stored in a desiccator for further analysis.

\section{SEM/EDS characterisation}

A scanning electron microscope (SEM) equipped with energy dispersive spectroscopy (EDS) was used to examine the surface morphology of each of the plated test specimens. A small portion of each of the specimens was cut and mounted on a stub. The specimens were examined in turn in the SEM, and electron micrographs were made of the representative areas of the surface at different magnifications. The EDS analysis was also done to determine the composition of the surface of the plated metal.

\section{Adhesion test}

The adhesion of the zinc coating to the steel substrate was tested by using cellotape fastened to the surface and later pulled off. This was then visually observed for any zinc stripping from the plated steel's surface. The plated surface was further scratched with a scalpel to test for the zinc adhesion. The specimens were too small for a bending test.

\section{Corrosion resistance testing of electroplated specimen}

Corrosion resistance of the electroplated mild steel was tested gravimetrically. Each of the plated mild steel test specimens was partially immersed in the seawater test environment. The seawater was topped up to replace the amount lost due to evaporation. Weight Loss measurements were taken every two days for a period of 24 days. The corresponding corrosion rates values were determined from these weight loss values by calculation using this formula:

C.R. $=87.6 \mathrm{~W} / \mathrm{DAT}$

Where $\mathrm{W}$ is the weight loss in milligrams, $\mathrm{D}$ is the density in $\mathrm{g} / \mathrm{cm}^{2}$, A is the area in $\mathrm{cm}^{2}$, and $\mathrm{T}$ is the time of exposure in hours.

\section{RESULTS AND DISCUSSION}

\section{Electrodeposition of zinc}

\section{No additive}

Presented in Fig. 2 (i), is the SEM micrograph of the surface of the mild test samples before zinc electrodeposition. Electrodeposition of zinc on mild steel test samples from acid-chloride solution without any additive showed no apparent porosity at the portion photographed with the SEM, Fig. 2 (ii). The crystals were distinct but difficult to describe in shape, with some coarse and fine particles interspersing each other but were closely packed. The surface crystals feature was not particularly smooth. The crystals were very much different from those plated with an additive. The coarse structure could be due to the absence of levelling agents in the acid solution. The viability of this type of zinc plating will certainly depend on the conditions under which the experiments are performed. The poor throwing power of the acid solution could be associated with the observed coarse crystal morphological structure of the plated sample surface. 


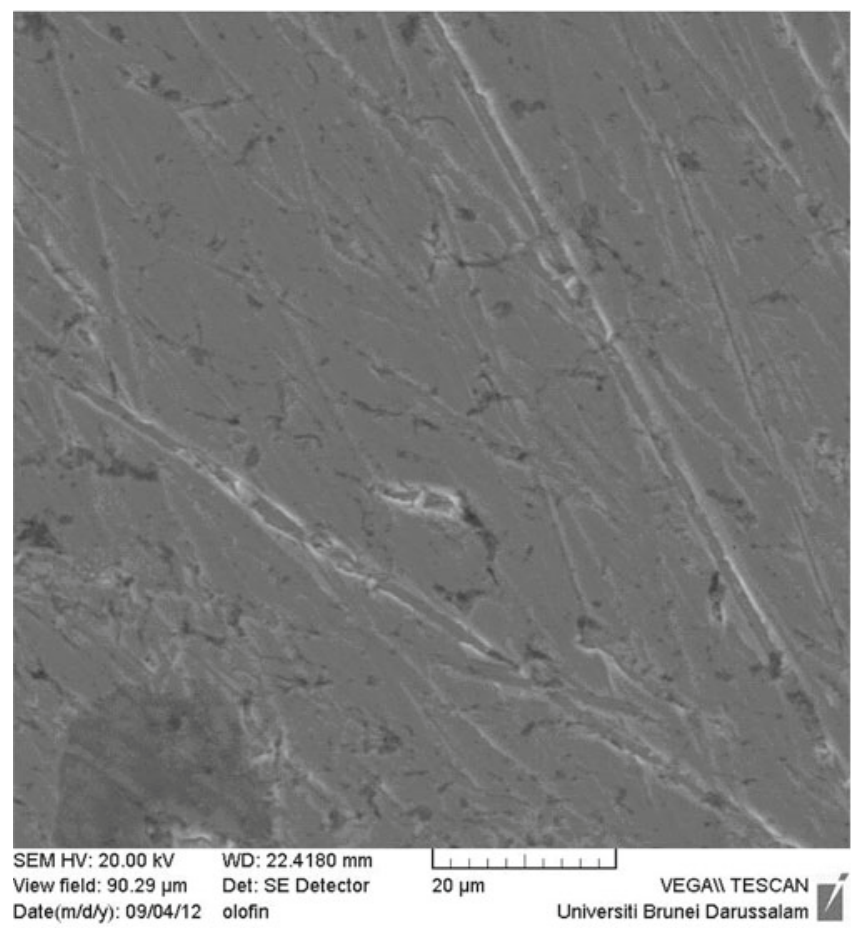

(i) Unplated

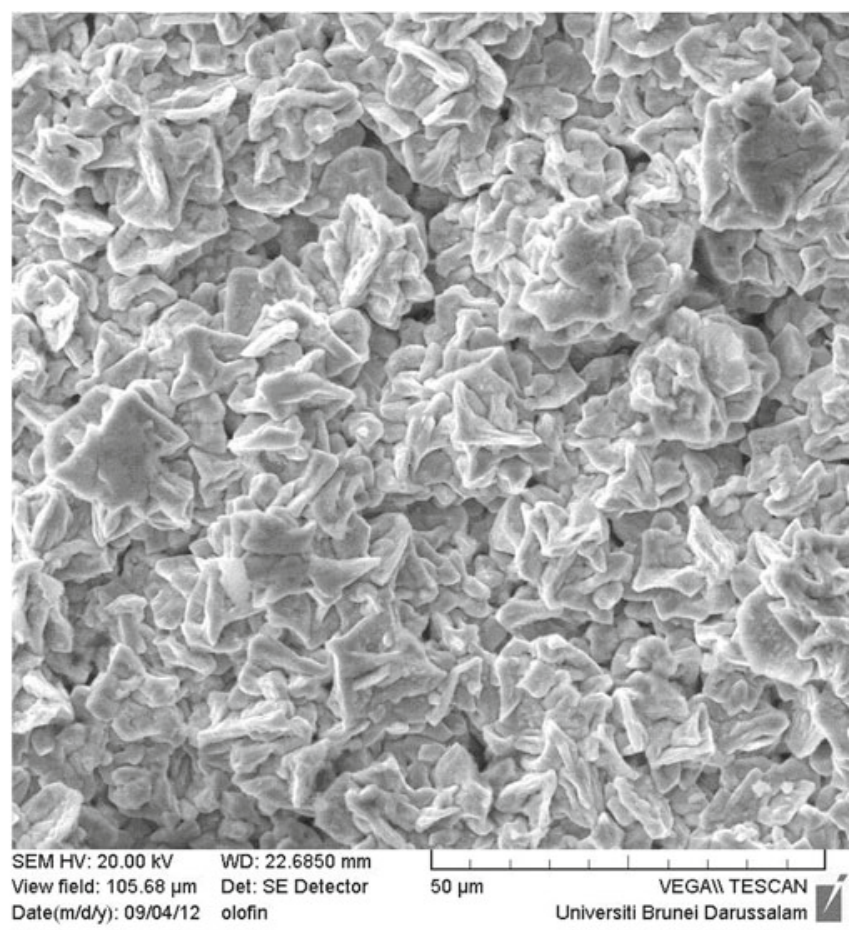

(ii) Plated without additive

Figure 2. SEM micrographs of mild steel test sample: (i) Unplated sample (ii) Plated without additive

\section{Same additive concentration and different plating time}

\section{$4 \mathrm{ml} / 50 \mathrm{ml}$ additive at 15 and18 minutes plating time}

The micrographs made with plating at 15 and 18 minutes respectively with the extract concentration of $4 \mathrm{ml} / 50 \mathrm{ml}$ of acid chloride solution is presented in Fig. 3. The surface microstructure is more of very fine grains, levelled and looks less bright. At the portions examined, there was no discernible porosity observed. The crystal particles were very close-packed and creating a well-defined surface microstructure. When compared

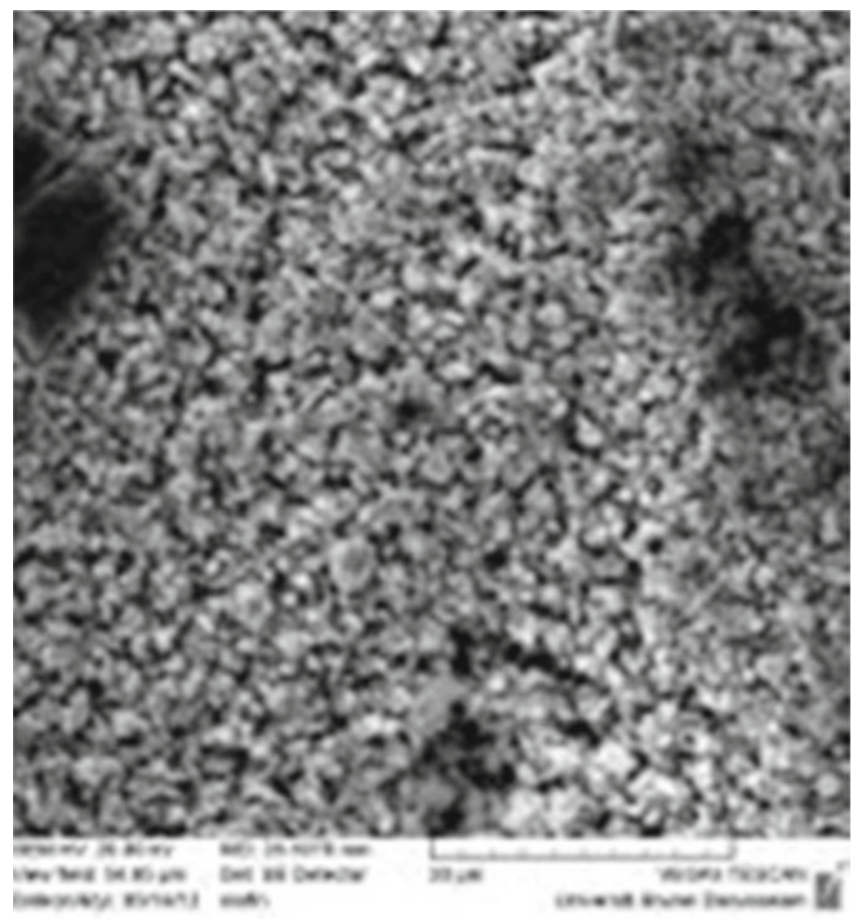

(i) with the Fig. 2 (ii), that is, with the one without added juice, a significantly clear difference in surface structure could be observed. Obviously the observed very fine grains and the levelling difference in surface morphology as evidenced in Fig. 3 (i-ii), emanated from the addition of the tobacco extract. The difference in surface morphology in Fig. 2 (i) and (ii) seems insignificant. However, Fig. 2 (ii) with 18 minutes plating time appears to have a better levelling effect. The complex chemical compositions of the tobacco extracts would have impacted the surface structure changes/modification. The unique

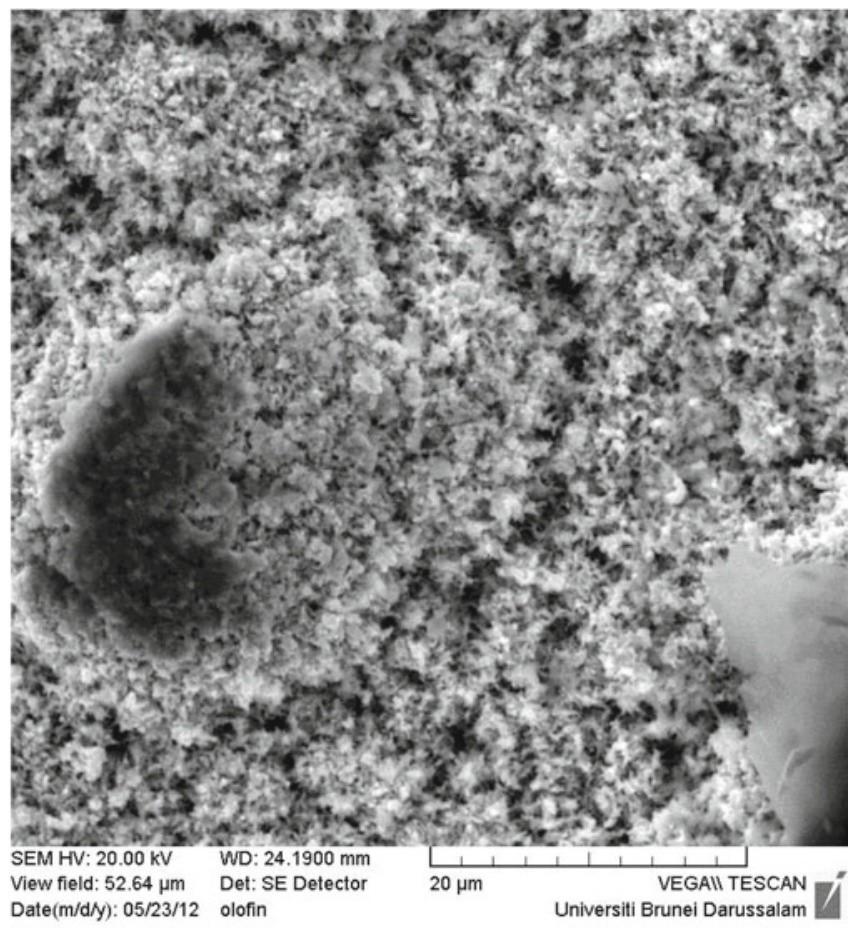

(ii)

Figure 3. SEM micrographs of steel surface after zinc plating with $4 \mathrm{ml} / 50 \mathrm{ml}$ of acid- chloride solution at (i) 15 and (ii) $18 \mathrm{mi}-$ nutes respectively 
microstructure observed in Fig. 3 (i-ii), is the evidence of good zinc electrodeposition. A densely packed surface structure, such as obtained here, is expected to give appreciable corrosion resistance performance. The brightening effect of the added juice extract was low due to the strong dark colour of the tobacco extracts. The mass of zinc deposited was weighed to be 24.3 and $28.3 \mathrm{mg}$ respectively, Table 2 .

\section{$5 \mathbf{m l} / \mathbf{5 0} \mathbf{~ m l}$ of additive at $\mathbf{1 5}$ minutes plating time}

The change in the extract additive concentration from $4 \mathrm{ml}$ to $5 \mathrm{ml}$ tobacco extract $/ 50 \mathrm{ml}$ of acid chloride solution and from 18 to 15 minutes plating time provided another different surface morphological structure as presented in Fig. 4 (i). The very little increase in the volume/ concentration of the extract brought about very significant surface morphological changes. Here, the surface crystals remained very refined and levelled as could be observed. The deposition looked dense and very closely parked. The samples' surface was not so bright visually due to the tobacco extract strong darkish colour. Even an attempt to bleach the solution extract with the activated carbon failed. The mass of the deposited zinc was $29.3 \mathrm{mg}$. There was no apparent porosity seen within the micrograph. It is expected that the plating will exhibit good corrosion protection sacrificially and cathodically.

\section{$5 \mathrm{ml} / 50 \mathrm{ml}$ additive at 18 minutes plating time}

Figure 4 (ii) shows the SEM micrograph of steel surface after zinc electrodeposition with $5 \mathrm{ml} / 50 \mathrm{ml}$ of acid chloride solution at $18 \mathrm{~min}$. In this micrograph, no porosity was observed at the portion(s) examined. The surface microstructure shows a densely and closed- packed feature and thus presenting a good surface morphology. The plating time here was 18 minutes and the concentration of the addition agent used also increased from $4 \mathrm{ml}$ to
$5 \mathrm{ml} / 50 \mathrm{ml}$ of acid chloride solution. It is thus plausible to associate the observed features here with concentration and plating time effect. A non-defective surface feature such as this has the positive implication of enhancing better surface corrosion protection. The plated zinc was expected to corrode sacrificially to protect the mild steel substrate. The surface crystals were fine and with good levelling. However, just as mentioned above, the darkish colour of tobacco solution extract affected the brightness of the plated surface. The mass of zinc deposited during the plating period was $24.6 \mathrm{mg}$.

\section{$6 \mathrm{ml} / 50 \mathrm{ml}$ additive at 15 minutes plating time}

The SEM micrograph of steel surface after zinc electrodeposition with $6 \mathrm{ml} / 50 \mathrm{ml}$ of acid chloride solution at 15 minutes is presented in Fig. 5 (i). In this experiment, there was an increase in the concentration of the additive while the plating time was decreased to 15 minutes. The crystal grains at all the magnifications presented here were very refined, well levelled and are closely similar in shape. The grains were well close-packed and thus presenting a smooth surface characteristics. In spite of the low brightness of the deposition, this plating was expected to give very good surface protection to the mild steel substrate. The mass of zinc deposited was $24.1 \mathrm{mg}$. The reduced plating time seemed to have no apparent adverse effect on the obtained zinc deposition. The increase in the additive concentration appeared to have made contribution to the observed fine-grained, smooth and levelled surface morphology. It is important to mention here again that the chemical composition of tobacco is indeed very complex. There is no doubt that these would have very great beneficial impact on the positive results that were recorded in this work.

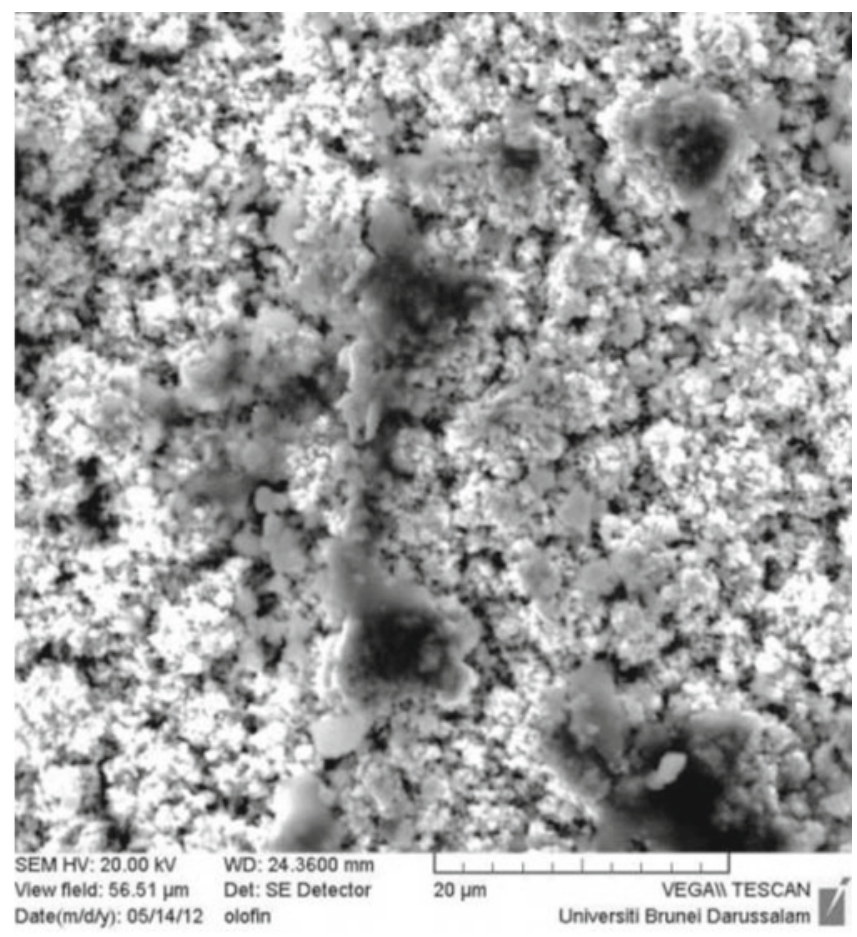

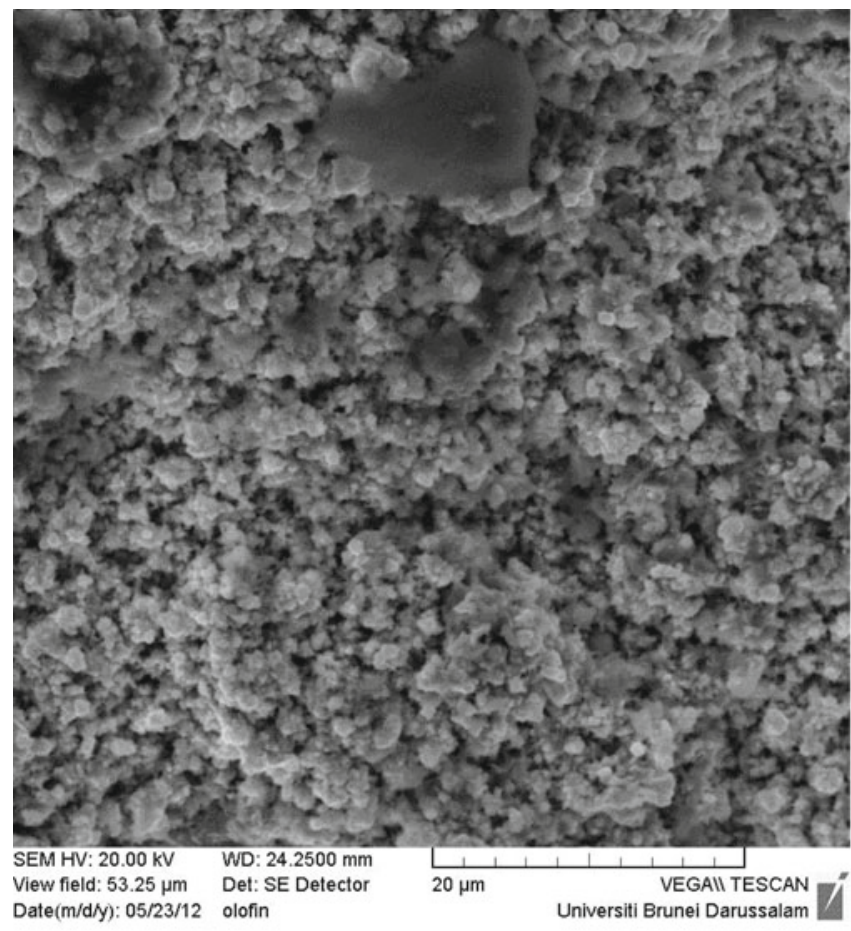

(i) (ii)

Figure 4. SEM micrographs of steel surface after zinc plating with $5 \mathrm{ml} / 50 \mathrm{ml}$ of acid chloride solution at (i) 15 minutes and (ii) 18 minutes respectively 


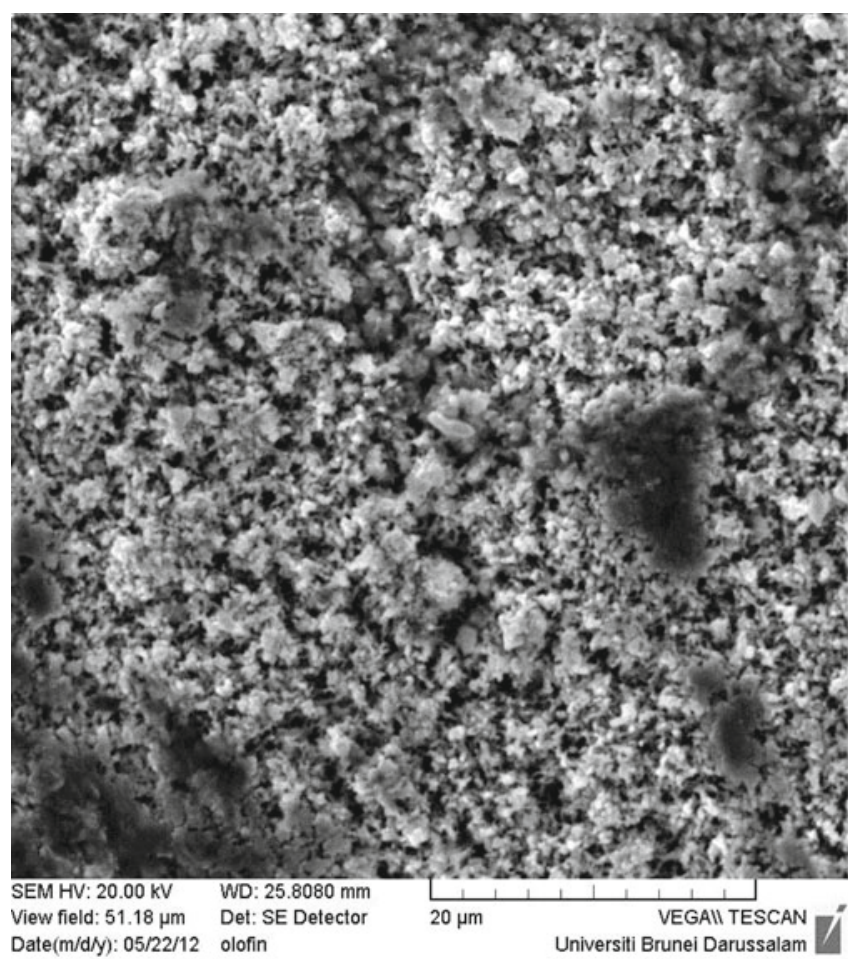

(i)

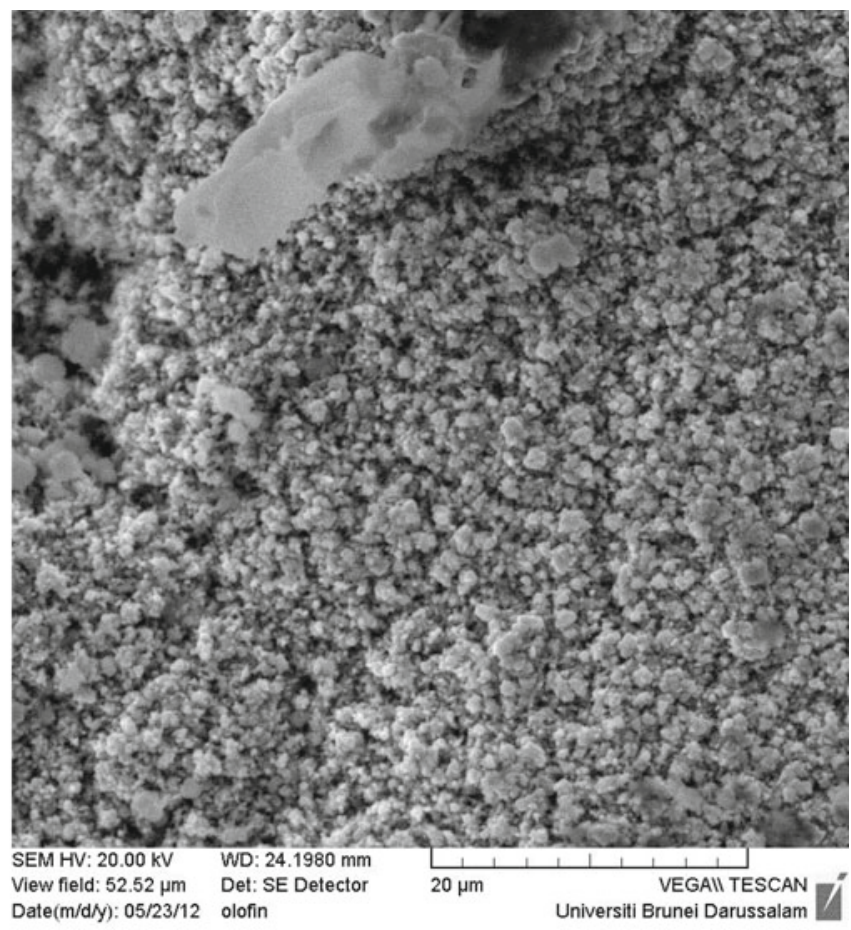

(ii)

Figure 5. SEM micrographs of steel surface after zinc plating with $6 \mathrm{ml} / 50 \mathrm{ml}$ of acid chloride solution at (i) $15 \mathrm{~min}$. and (ii) 18 minutes respectively

\section{$6 \mathrm{ml} / 50 \mathrm{ml}$ additive at 18 minutes plating time}

The results obtained for the plating of zinc on mild steel in this work, as presented in Fig. 5 (ii), using $6 \mathrm{ml}$ tobacco extract $/ 50 \mathrm{ml}$ of acid chloride solution at $18 \mathrm{mi}-$ nutes plating time were not much different from what was obtained with during 15 minutes, using the same concentration of the additive. The grain crystals looked the same in feature but more refined and more compact in Fig. 5 (ii). The time effect also made a contribution to the morphology of the plated surface though not too significant in this case.

The fineness and the compactness of the surface morphology in Fig 5 (ii) is therefore expected to give a better surface protective property in terms of corrosion resistance. It is also important to mention that the 18-minutes plating time enhanced its levelling behaviour.

\section{Different additive concentrations and same plating time}

Presented in Fig. 6, are the various SEM micrographs for the samples plated at different concentrations of 4, 5, and $6 \mathrm{ml} / 50 \mathrm{ml}$ and at the same plating time of: (A) 15 minutes and (B) 18 minutes respectively. The surface morphology of each of these micrographs had been described above. They are represented in Fig. 6 for surface structural comparison. All the micrographs used are at the magnification of $x$ 5000. In general the plating time of 18 minutes at all the concentrations used seem to have finer microstructure and better levelling feature than the plating time of 15 minutes. The surface morphology for each of the plating time for the three different concentrations bears very close similarities.

\section{EDS Analysis}

The result of energy dispersive analysis (EDS) of Fig. 3 (iii) is presented in Fig. 7. The surface microstructure showed it to be mainly zinc and a little amount of tin which could be in trace form in the zinc metal that was co-deposited.

\section{CORROSION RESISTANCE OF THE ZINC PLATED MILD STEEL}

Figures 8 to 11 show the various results obtained for the weight loss and corrosion rate of the tested samples in seawater environment. The results of the weight- loss method and the calculated corresponding corrosion rates of some of the zinc plated mild steel samples that were tested in the sea water medium are presented in Figs. 8 to 11 . Fig. 8 shows the curves of the weight loss versus the exposure time at different concentrations of tobacco extract additive and at the plating time of 15 minutes for each of the test samples.

All the plated samples showed better corrosion resistance than the unplated samples as expected. While the unplated sample recorded a weight loss of $39.70 \mathrm{mg}$ on the $30^{\text {th }}$ day of the experiment, the sample plated with $6 \mathrm{ml}$ tobacco solution extract $/ 50 \mathrm{ml}$ acid chloride solution recorded a weight loss value of $11.30 \mathrm{mg}$ at the same period of 30 days of the experiment. The weight loss recorded for the plated samples was due mainly to the anodic zinc dissolution in the test environment after a long period of 30 days.

The corresponding corrosion rates curves, Fig. 9 followed the same trend as above. The unplated test sample recorded the highest corrosion rate $(0.1631$ and $0.1666 \mathrm{~mm} / \mathrm{yr}$ ) on the $20^{\text {th }}$ and $30^{\text {th }}$ day of the experiment respectively; while the sample plated with $5 \mathrm{ml}$ solution extract $/ 50 \mathrm{ml}$ acid chloride solution recorded the corrosion rates of 0.0691 and $0.06694 \mathrm{~mm} / \mathrm{yr}$ at the same peeriod of the experiment respectively. The difference 


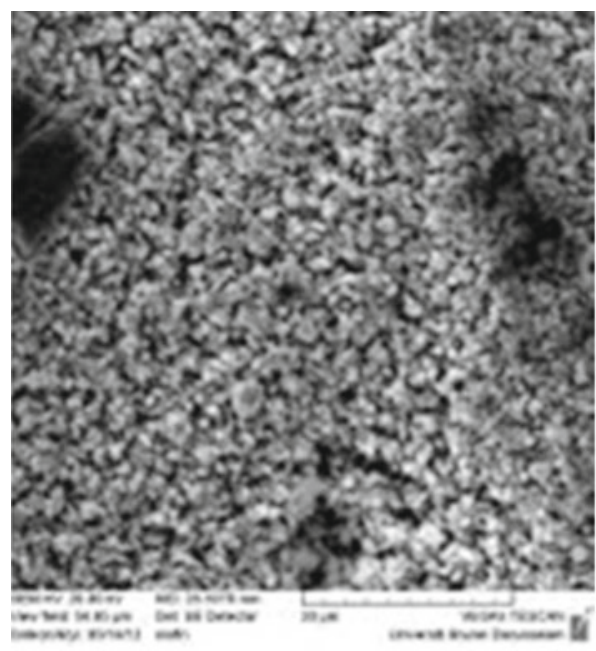

(i)

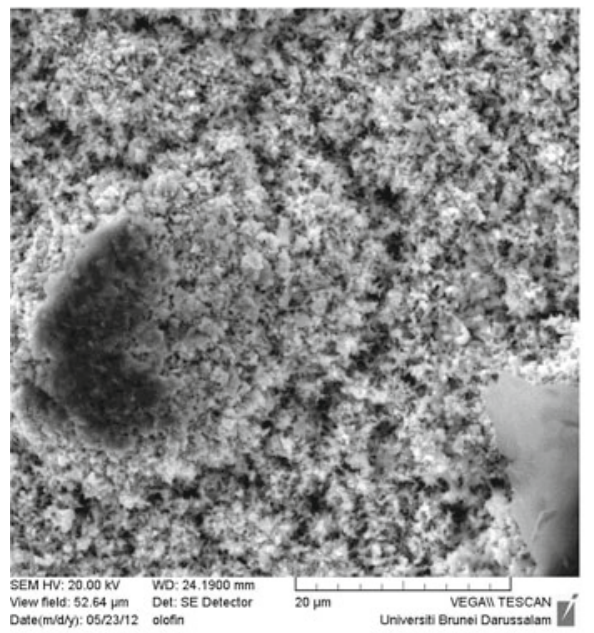

(i)

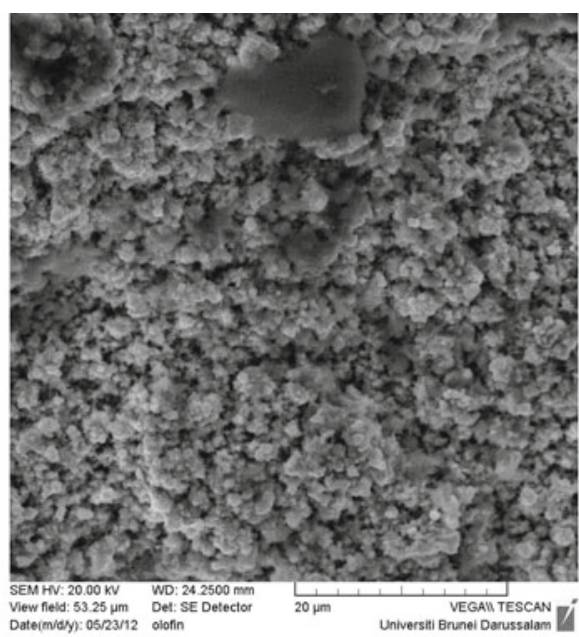

(ii)

(A)

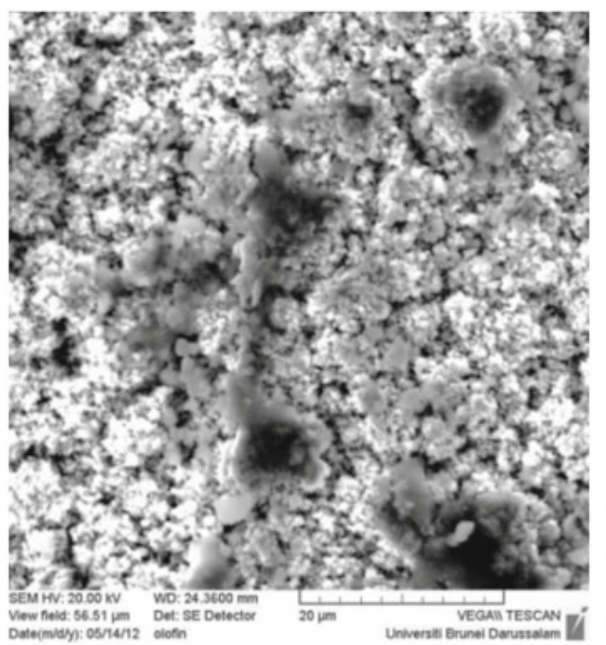

(ii)

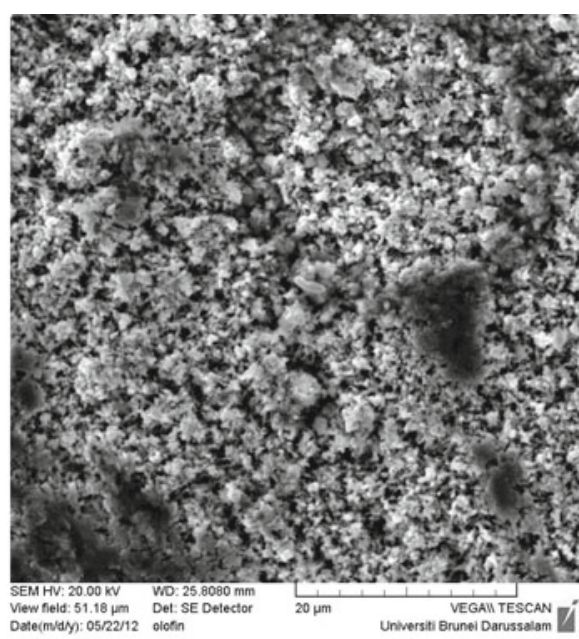

(iii)

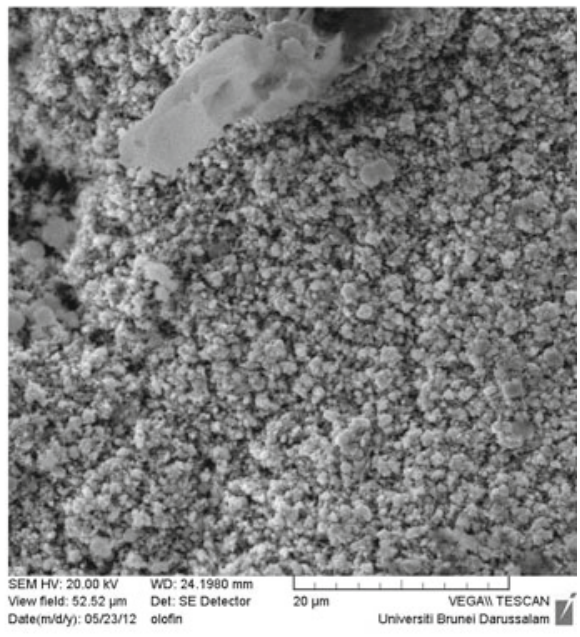

(iii)

(B)

Figure 6. SEM micrographs for the samples plated at different concentrations and at the same plating time: (A) - (i) 4 ml, (ii) $5 \mathrm{ml}$ and (iii) $6 \mathrm{ml} / 50 \mathrm{ml}$ for 15 minutes; (B) (i) $4 \mathrm{ml}$, (ii) $5 \mathrm{ml}$, and (iii) $6 \mathrm{ml}$ at 18 minutes respectively

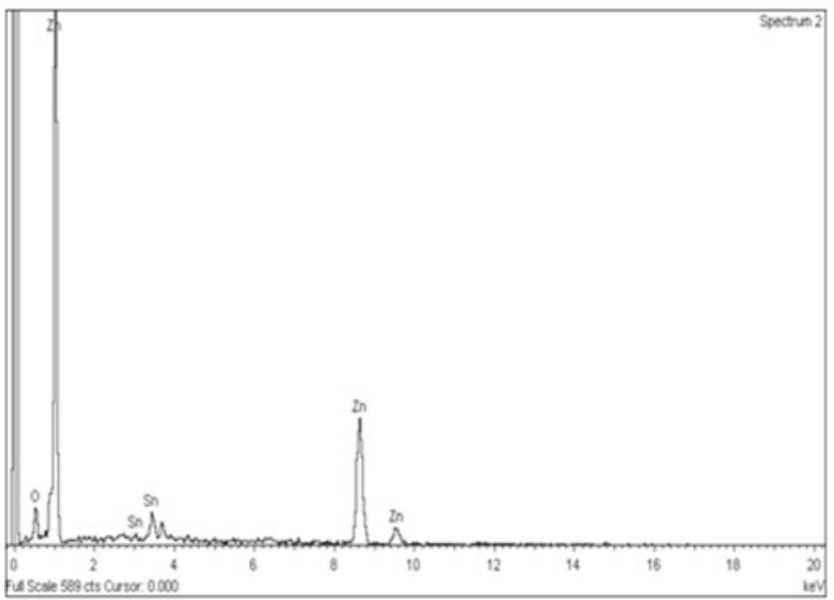

Figure 7. EDS analysis of the plated surface of sample in Fig. 3 (ii)

in corrosion rate is significant. The results obtained for the corrosion rate test with $4 \mathrm{ml} / 50 \mathrm{ml}$ additive for 15 minutes plating time, was out of trend of corrosion performance. It is difficult to explain why the specimen without additive showed better corrosion resistance in this instance. However, any porosity as could be obse-

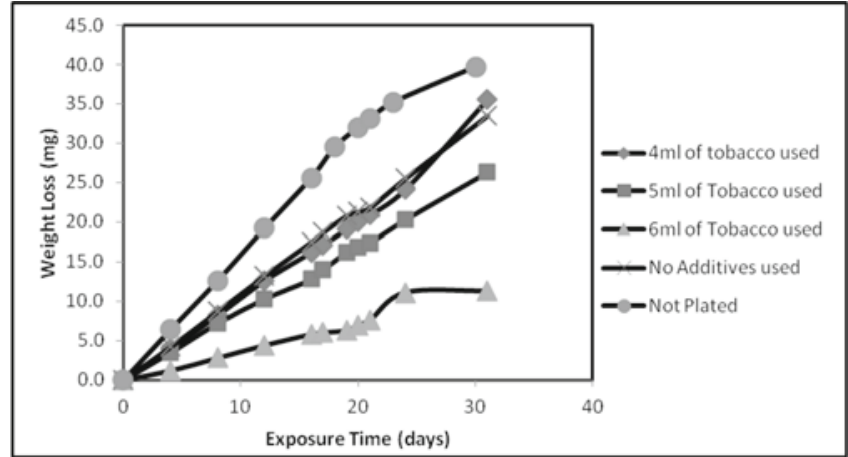

Figure 8. Variation of weight loss with exposure time for the zinc electrodeposited mild steel - sample in seawater. (Variable additive concentrations and 15 minutes plating time)

rved in Fig. 3 would provide a small anodic site on the mild steel substrate in comparison with a large cathodic zinc plated portion with the consequence of increased rate of corrosion reactions such as observed. It should be noted also that additives function more as levelling and brightening agents. 


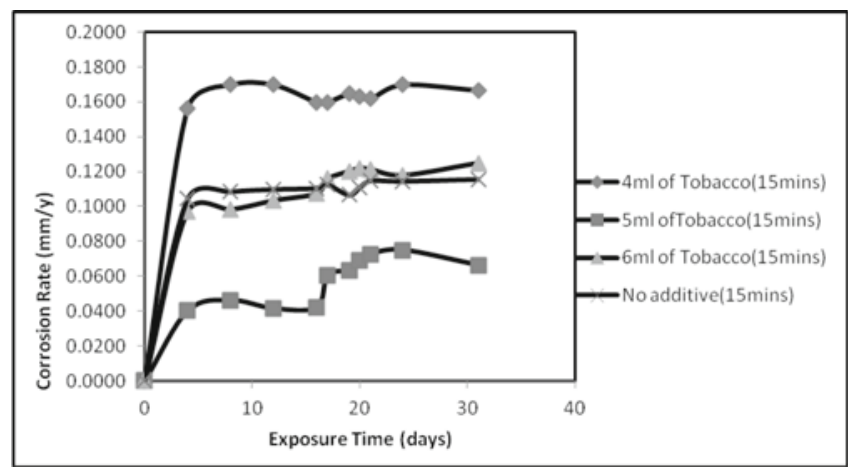

Figure 9. Variation of corrosion rate with exposure time for the zinc plated mild steel samples in seawater. (Variable additive concentrations and 15 minutes plating time)

While maintaining the other plating parameters, the results presented in the curves in Figs. 10 (weight loss) and Fig. 11 (corrosion rates) were obtained with the plating time of 18 minutes. Just as in Fig. 8, the trend of corrosion resistance for the weight loss values looked similar. The samples plated with $5 \mathrm{ml}$ solution extracts (as additive), gave the lowest weight loss $(12.80 \mathrm{mg}$ ) on the $30^{\text {th }}$ day of the experiment while the lowest corrosion rate. $0.0485 \mathrm{~mm} / \mathrm{yr}$ was recorded for the sample tested with $6 \mathrm{ml}$ tobacco extract at the same period of the experiment.

In all, as could be seen in the results as contained in the curves, the plated samples were more corrosion resistant and hence more protective. Again this is due to deposited zinc going into dissolution to sacrificially protect the mild steel substrate. Also from the results, it could be inferred that the rate/magnitude of zinc dissolution is minimal.

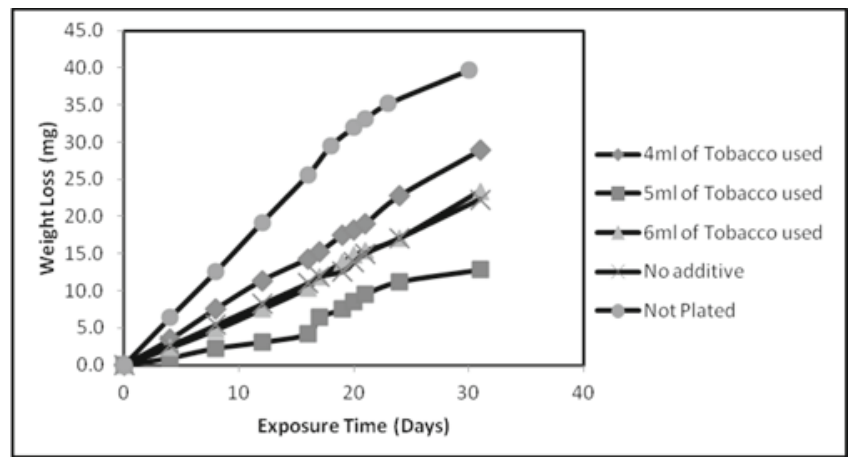

Figure 10. Variation of weight loss with exposure time for the zinc plated mild steel samples in seawater. (Variable additive concentrations and 18 minutes plating time)

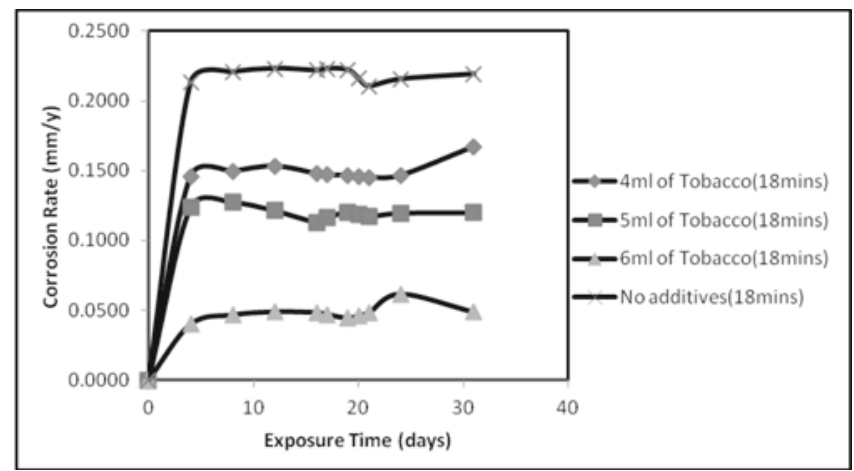

Figure 11. Variation of corrosion rate with exposure time for the zinc plated mild steel samples in seawater. (Variable additive concentrations and 18 minutes plating time)
It is important to mention that the results obtained for corrosion resistance performance of the samples bear very close correlation with the surface microstructure in the micrographs and also to the mass of zinc depodsited on the plated portions. The more compact the surface crystal particles; the finer the crystal structure and the less amount of porosity in the plated samples, the more the corrosion resistance observed.

The cellotape test confirmed the strong adhesion of the zinc to the steel surface. Visual inspection could not reveal any visible particle removed from the plated steel surface.

\section{CONCLUSIONS}

Using tobacco (Nicotiana tobaccum) extract as the addition agent gave good zinc electrodeposition with fine, dense and close- packed crystal grains on mild steel surface in the acid zinc chloride solution.

Characterisation of the zinc plated surface of the mild steel substrate showed different surface morphology depending upon the plating conditions.

The electrodeposition process was sensitive to changes in additive concentration and plating time. Any variation in the plating parameter produced an enirely new and different surface crystal strucure.

The plated samples showed good corrosion resistance in the seawater test when compared with the unplated samples and thus confirming their expected protective capabiliy.

The plating produced less than bright deposition due to the tobacco extract's colour that was difficult to decolourise using activated carbon. Though not as bright as the cyanide bath, the surface structures obtained indicate that the plating can serve several useful protective purposes that could be technologically and economically viable.

The additive used was non-toxic agricultural product that is environment friendly.

\section{ACKNOWLEDGEMENT}

The authors acknowledge the laboratory investigation contribution of Miss Yvonne N. Allanah, and also, the Department of Mechanical Engineering, Covenant University, Ota for the provision of research facilities for this work.

\section{LITERATURE CITED}

1. American Society for Metals, Metals Handbook, $9^{\text {th }}$ Edition, 5 (1982) 250-252.

2. Pushpavanam, M. (1986). Role of additives in bright zinc deposition from cyanide free alkaline baths. Plat. Surf. Finish., 73: 47-47.

3. Schneider, S. (1987). "Zinc Plating" Plating and Surf. Fin. 74, 20 .

4. D`Angelo, M.P. (1986). Zinc Plating Without Cyanide: Two decades of Progress, Plating and Surf. Fin., 73, 9 (1986) 23.

5. Loto, C.A. \& Olefjord, I. (1992a). Influence of organic additives on the surface characteristics of zinc electrodeposition on mild steel in acid chloride solutions: $\mathrm{pH}$, bath composition and time variation effects Corr. Prev. and Control J., 39, 142-149.

6. Loto, C.A. \& Olefjord, I. (1990). Corr. Prev. and Control J., 37, 5, 158-163.

7. Loto, C.A., Olefjord, I. \& Mattson, H. (1992b). Surface effects of organic additives on the electrodeposition of zinc 
on mild steel in acid chloride solution. Corros. Prev. Control J., 39, 82-88.

8. Darken, J. (1979). Recent progress in bright plating from zincate electrolytes Trans. IMF, 57, 145-145.

9. Venkatesha, T., Balachandra, J., Mayanna, S.M. \& Dambal, R.P. (1987). Effect of glycine and thiourea as brighteners in acid zinc sulfate bath. Plat. Surf. Finish., 74: 77-80.

10. Kanagalarasa, V. \& Venkatesha, T.V. (2011). Studies on electrodeposition of $\mathrm{Zn}-\mathrm{MoS}$ nanocomposite coatings on mild steel and its properties. J. Solid State Electrochem., 10, 1-9, DOI: $1007 / \mathrm{s} 10008-011-1475-8$.

11. Nayana, K., Venkatesha, T.V., Praveen, B.M. \& Vathsa, K. (2011). Synergistic effect of additives on bright nanocrystalline zinc electrodeposition. J. Appl. Electrochem, 41, 39-49. DOI 10.1007/s10800-010-0205-8.

12. Schlesinger, M. \& Paunovic, M. (2000). Electrodeposition of Zinc and Zinc Alloys in Modern Electroplating. 4th Edn., John Wiley and Sons, New York, 423-460.

13. Zemanova, M. (2009). Corrosion resistance of zinc electrodeposited from acidic and alkaline electrolytes using pulse current. Chem. Papers, 63, 574-578. DOI: 10.2478/ s11696-009-0051-5.

14. Loto, C.A. (2005). Inhibition of cashew juice on the corrosion of mild steel in sulphuric acid. Corr. Prev. \& Control, Vol. 52, 1, 13-22.

15. Okafor, P.C. (2007). Pigment and Resin Technology, 36, (5).

16. Davis, G.D. \& Fraunhofer, J.A. (2003). Tobacco plant as environmentally benign corrosion inhibitors, Materials Performance, 2: 56-60.

17. Fraunhofer, J.A. (1995). Tobacco Extract Composition and Methods, U.S. Patent 43, 941.

18. Davis, G.D, Fraunhofer, J.A, Krebs, L.A. \& Dacres, C.M. (2001). CORROSION/2001, Paper No. 58 (Houston, TX: NACE).

19. Fraunhofer, J.A. (2000). Advanced Materials and Processes, 158, 33.

20. Loto, C.A. (2003). The effect of bitter leaf extract on the inhibition of mild steel in $\mathrm{HCl}$ and $\mathrm{H}_{2} \mathrm{SO}_{4}$. Corr. Pre v. \& Control, 50 (1): 43-49.

21. Loto, C.A. (2000). The effect of Anarcadium Occidentale (cashew) juice extract on the corrosion of mild steel in hydrochloric acid. Corro. Prev. and Control, 47 (2) 50-56.

22. Loto, C.A. (2001). The effect of mango bark and leaf extract solution additives on the corrosion inhibition of mild steel in dilute sulphuric acid. Corr. Prev. and Control, 48 (1) 38-41 \& 59-65.

23. WHO, IARC (1985). Monogrs. on the Eval. of the carcino. Risk of Chem. to Humans, 37, 9. 